\title{
QUALIDADE MICROBIOLÓGICA DE LINGÜIÇAS MISTAS DO TIPO FRESCAL PRODUZIDAS NA CIDADE DE PELOTAS(RS)
}

\author{
WLADIMIR PADILHA DA SILVA * \\ ELIEZER AVILA GANDRA ** \\ EDUARDA HALLAL DUVAL *** \\ MÁRCIA MONKS JANTZEN **** \\ CRISTIANE TESSMANN ***** \\ ANDRÉIA SALDENHA LIMA *
}

\begin{abstract}
Foram avaliadas as condições higiênico-sanitárias de lingüiças mistas do tipo frescal, provenientes de 4 frigoríficos submetidos à inspeção sanitária estadual, e comercializadas em Pelotas (RS). Os resultados obtidos foram interpretados pela legislação vigente (RDC n 12/01) e pela anterior (Portaria 451), ambas do Ministério da Saúde (Brasil). Verificou-se que 17,86\% das 32 amostras estavam contaminadas com Salmonella sp e 3,57\% apresentaram Coliformes fecais acima dos parâmetros permitidos pela legislação em vigor. Com a alteração da legislação, a probabilidade de se encontrar amostras de lingüiça mista frescal contaminada por Coliformes fecais passou de $23,27 \%$ para $5,6 \%$.
\end{abstract}

PALAVRAS-CHAVE: LINGÜIÇA-SALMONELA; LINGÜIÇA-COLIFORMES FECAIS, LINGÜIÇA-LEGISLAÇÃO BRASILEIRA.

* Doutor, Professor Adjunto, Laboratório de Microbiologia de Alimentos (MICROBIAL), Departamento de Ciência e Tecnologia de Alimentos (DCTA), Faculdade de Agronomia Eliseu Maciel (FAEM), Universidade Federal de Pelotas (UFPel), Campus Universitário, Pelotas (RS). (e-mail: silvawp@ufpel.tche.br).

** Engenheiro de Alimentos, Mestrando em Ciência e Tecnologia Agroindustrial, MICROBIAL, DCTA, FAEM, UFPel, Pelotas (RS).

*** Acadêmica de Medicina Veterinária, MICROBIAL, DCTA, FAEM, UFPel, Pelotas (RS).

**** Mestre, Doutoranda em Ciência e Tecnologia Agroindustrial, MICROBIAL, DCTA, FAEM, UFPel, Pelotas, RS.

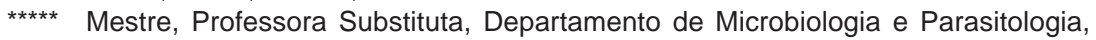
UFPel, Pelotas, RS.

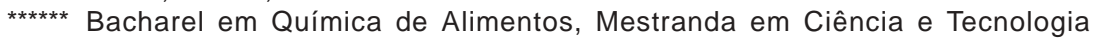
Agroindustrial MICROBIAL, DCTA, FAEM, UFPel, Pelotas, RS. 


\section{INTRODUÇÃO}

As lingüiças mistas do tipo frescal são embutidos cárneos que apresentam grande aceitação por parte dos consumidores no Rio Grande do Sul. Entretanto, pelo fato de não sofrerem nenhum tratamento térmico em seu processamento, pelas suas características intrínsecas e por serem submetidas a intenso manuseio poderão veicular microrganismos patogênicos.

Para que os produtos processados em frigoríficos, e submetidos à Inspeção Sanitária Estadual, possam ser comercializados devem estar de acordo com os padrões estabelecidos pela Agência Nacional de Vigilância Sanitária (ANVISA), do Ministério da Saúde. Em vigência desde 1997, a Portaria $n^{\circ} 451$ foi revogada em 2 de janeiro de 2001 pela Resolução n. 12 (BRASIL, 2001). Embora diversos microrganismos patogênicos possam ser veiculados por lingüiças tipo frescal, a atual legislação prevê apenas a análise de Salmonella sp e a enumeração de Estafilococos coagulase positiva, de Clostridios sulfito redutores e Coliformes a $45^{\circ} \mathrm{C}$. Além disso, a nova legislação ampliou os limites máximos estabelecidos para Coliformes a $45^{\circ} \mathrm{C}$, Estafilococos coagulase positiva e Clostridios sulfito redutores para esse tipo de alimento.

Neste trabalho foram avaliadas as condições higiênico-sanitárias de lingüiças mistas do tipo frescal, produzidas com carne bovina e suína, provenientes de 4 frigoríficos fiscalizados pelo Serviço de Inspeção Sanitária Estadual e comercializadas em Pelotas (RS). Os resultados obtidos foram interpretados pela legislação vigente (RDC no 12/01) e pela anterior (Portaria 451/97), ambas do Ministério da Saúde.

\section{MATERIAL E MÉTODOS}

Foram avaliadas 32 amostras de lingüiça mista (carne bovina e suína) do tipo frescal, produzidas na cidade de Pelotas (RS). As amostras foram coletadas na expedição para comercialização e submetidas às determinações microbiológicas de Salmonella sp, Estafilococos coagulase positiva, Clostridios sulfito redutores e Coliformes a $45^{\circ} \mathrm{C}$, utilizando-se metodologia proposta pela FDA (1992).

Para o isolamento de Salmonella sp foi realizado pré-enriquecimento em água peptonada tamponada $\left(24 \mathrm{~h} \mathrm{a} 37^{\circ} \mathrm{C}\right)$ e enriquecimento seletivo em Caldo Rappaport-vassiliadis $\left(24 \mathrm{~h} \mathrm{a} 42^{\circ} \mathrm{C}\right)$ e Caldo Tetrationato $\left(24 \mathrm{~h} \mathrm{a} 37^{\circ} \mathrm{C}\right)$, 
seguido por semeadura em ágares XLD e Hektoen-enteric (HE), sendo ambos incubados por $24 \mathrm{~h} \mathrm{a} 37^{\circ} \mathrm{C}$. Colônias típicas foram submetidas à identificação bioquímica em Ágar Tríplice Ferro, Ágar Lisina Ferro e Ágar Urease $\left(24 \mathrm{~h}\right.$ a $\left.37^{\circ} \mathrm{C}\right)$ e as que apresentaram reação bioquímica característica à identificação sorológica, utilizando-se os soros polivalentes anti-salmonella somático e flagelar (Probac).

Na enumeração de Estafilococos coagulase positiva utilizou-se Ágar BairdParker, que foi incubado por $48 \mathrm{~h}$ a $37^{\circ} \mathrm{C}$ e 5 colônias características de cada placa foram submetidas a coloração diferencial de Gram, produção de catalase, de termonuclease e de coagulase livre.

A avaliação de Coliformes a $45^{\circ} \mathrm{C}$ (Coliformes fecais) foi realizada pela técnica do Número Mais Provável (NMP), utilizando-se Caldo Lauril Sulfato de Sódio $\left(48 \mathrm{~h}\right.$ a $\left.37^{\circ} \mathrm{C}\right)$, na etapa presuntiva. Os tubos positivos foram inoculados em Caldo Verde Bile Brilhante $\left(48 \mathrm{~h}\right.$ a $\left.37^{\circ} \mathrm{C}\right)$ para confirmação de coliformes totais e em Caldo EC $\left(24 \mathrm{~h}\right.$ a $\left.45,5^{\circ} \mathrm{C}\right)$ para confirmação de Coliformes fecais. Na pesquisa de Clostridios sulfito redutores utilizou-se o meio Ágar Triptose Sulfito Cicloserina em atmosfera anaeróbica (24h a $\left.46^{\circ} \mathrm{C}\right)$.

A análise estatística foi realizada seguindo-se as recomendações de BOOK (1977). Utilizou-se o teste Z para avaliar a probabilidade percentual de encontrar amostras com níveis de contaminação por coliformes fecais enquadrados nos padrões estabelecidos pela RDC n.12/01 (BRASIL, 2001) e pela Portaria 451/97 (BRASIL, 1997), cujos parâmetros podem ser visualizados na Tabela 1.

\section{TABELA 1 - PADRÕES MICROBIOLÓGICOS MÁXIMOS PARA PRODUTOS CÁRNEOS RESFRIADOS OU CONGELADOS "IN NATURA" ESTABELECIDOS PELA PORTARIA N 451/ 97 E PELA RESOLUÇÃO RDC N¹2/01 DA ANVISA}

\begin{tabular}{|c|c|c|}
\hline Microrganismo & $451 / 97$ & RDC 12/01 \\
\hline Salmonella sp. & AusCfécia em $25 \mathrm{~g}$ & AusOf́cia em $25 \mathrm{~g}$ \\
\hline Estafilococos Coagulase Positiva ${ }^{a}$ & $10^{3} \mathrm{UFC} / \mathrm{g}$ & $5 \times 10^{3} \mathrm{UFC} / \mathrm{g}$ \\
\hline Coliformes a $45^{\circ} \mathrm{C}^{\mathrm{b}}$ & $5 \times 10^{2} \mathrm{NMP} / \mathrm{g}$ & $5 \times 10^{3} \mathrm{NMP} / \mathrm{g}$ \\
\hline Clostridios Sulfito Redutores a $46^{\circ} \mathrm{C}$ & $5 \times 10^{2} \mathrm{NMP} / \mathrm{g}$ & $3 \times 10^{3} \mathrm{NMP} / \mathrm{g}$ \\
\hline
\end{tabular}

a Staphylococcus aureus pela Portaria N 451/97.

${ }^{b}$ Coliformes fecais pela Portaria $N^{\circ} 451 / 97$. 


\section{RESULTADOS E DISCUSSÃO}

As lingüiças mistas do tipo frescal são produtos com alta predisposição para contaminações, provenientes das matérias-primas, ingredientes e tripas ou envoltório. De acordo com os resultados obtidos verificou-se a ocorrência de Salmonella sp em 17, $86 \%$ das amostras (Tabela 2), as quais estavam, portanto, em desacordo com os padrões da legislação vigente (Resolução RDC n¹2/01).

\section{TABELA 2 - AVALIAÇÃO MICROBIOLÓGICA DE 32 AMOSTRAS DE LINGÜIÇA MISTA FRESCAL UTILIZANDO-SE OS PARÂMETROS ESTABELECIDOS PELA PORTARIA 451/ 97 E RDC N ${ }^{\circ} 12 / 01$ DA ANVISA}

\begin{tabular}{llccc}
\hline Microrganismo & Legisla ${ }^{\mathrm{a}} \mathrm{O}$ & Par metro & $\begin{array}{c}\mathrm{N}^{0} \text { de amostras em } \\
\text { desacordo }\end{array}$ & $\begin{array}{c}\text { Total de } \\
\text { amostras }\end{array}$ \\
\hline Salmonella sp. & RDC 12 & AusCracia em 25 g & 5 & 32 \\
& $451 / 97$ & AusCfacia em 25 g & 5 & 32 \\
ECP $^{\mathrm{a}}$ & $\mathrm{RDC} 12$ & $<5 \times 10^{3} \mathrm{UFC} / \mathrm{g}$ & 0 & 32 \\
& $451 / 97$ & $<10^{3} \mathrm{UFC} / \mathrm{g}$ & 0 & 32 \\
Coliformes a 45 $^{\circ} \mathrm{C}^{\mathrm{b}}$ & $\mathrm{RDC} 12$ & $<5 \times 10^{3} \mathrm{NMP} / \mathrm{g}$ & 1 & 32 \\
& $451 / 97$ & $<5 \times 10^{2} \mathrm{NMP} / \mathrm{g}$ & 7 & 32 \\
$\mathrm{CSR}^{\mathrm{C}}$ & $\mathrm{RDC} \mathrm{12}$ & $<3 \times 10^{3} \mathrm{NMP} / \mathrm{g}$ & 0 & 32 \\
& $451 / 97$ & $<5 \times 10^{2} \mathrm{NMP} / \mathrm{g}$ & 0 & 32 \\
\hline
\end{tabular}

a Staphylococcus aureus pela Portaria N 451/97 ou Estafilococos Coagulase Positiva pela RDC 12.

${ }^{b}$ Coliformes fecais pela Portaria $N^{\circ} 451 / 97$.

c Clostrídios sulfito redutores.

Salmonella sp tem sido um dos principais microrganismos envolvidos em surtos de toxinfecção alimentar em todo o mundo. No Brasil, esse comportamento pode ser confirmado nos Estados em que há adequado registro dos casos de doenças de origem alimentar. No Rio Grande do Sul, de acordo com Divisão de Vigilância Sanitária (18), do total de 1037 surtos investigados no período entre 1987 e 1998, esse microrganismo foi responsável por 334 casos (32\%). No Estado de São Paulo esse patógeno originou 33,5\% dos surtos ocorridos no período entre 1994 e 1998 (11). 
A taxa de isolamento de Salmonella sp em produtos cárneos tem se mostrado bastante variável em diferentes pesquisas conduzidas no Brasil. Pode-se citar os trabalhos realizados em Curitiba (PR) (9), em Cuiabá (MT) (17), em Botucatu (SP) (16) e em Campinas (SP) (4), em que foi isolada em $2 \%, 35,3 \%, 10 \%$ e $2,8 \%$ das amostras, respectivamente. LOGUÉRCIO et al. (2001) pesquisaram este patógeno em 40 amostras de lingüiça suína comercializadas em Pelotas (RS) e isolaram Salmonella sp em $5 \%$ das mesmas. MARQUES et al. (2001), pesquisando lingüiças do tipo frescal comercializadas no município de Lavras (MG), não isolaram Salmonella sp em nenhuma das 20 amostras analisadas. Da mesma forma, GARCIA et al. (2000) não encontraram este patógeno em 60 amostras de lingüiça do tipo frescal comercializadas em Londrina (PR).

FERREIRA e SOBRINHO (2001) avaliaram amostras de carne bovina e suína comercializadas em São Luis (MA). Encontraram Salmonella sp em 4,17\% das amostras de carne bovina, mas não de carne suína. MOREIRA et al. (2001) pesquisaram a presença de Salmonella sp nas diferentes etapas da linha de processamento de lingüiça mista, em miniindústria de embutidos localizada na cidade de Araraquara (SP), e não isolaram o patógeno nos pontos amostrados, incluindo a matéria-prima (carne bovina e suína) e o produto final. Neste estudo não foram avaliadas as fontes de contaminação, apenas o produto final. Entretanto, a alta taxa de contaminação por Salmonella sp demonstra que há risco à saúde pública, evidenciando a necessidade de maior controle de matérias-primas e processos envolvidos na fabricação de lingüiça mista frescal em Pelotas.

S. aureus é a bactéria mais importante do grupo dos Estafilococos coagulase positiva, entretanto outras duas espécies, $S$. intermedius e $S$. hiycus também têm sido implicadas em surtos de intoxicação alimentar. No Rio Grande do Sul $12,71 \%$ do total de 1037 surtos investigados entre 1987 e 1998 foram atribuídos à S. aureus (18). Neste trabalho foram isolados Estafilococos coagulase positiva em 18 das 32 amostras analisadas, mas com contagens sempre abaixo de $10^{3}$ unidades formadoras de colônia por grama de produto (UFC/g) (Tabela 2). Tratandose de produto frescal, a microbiota acompanhante pode estar influenciando a multiplicação desse grupo bacteriano. DELAZARI et al. (1978) verificaram que mesmo em amostras de lingüiças inoculadas com $S$. aureus, esse microrganismo não alcançou níveis de população maiores que $10^{5} \mathrm{UFC} / \mathrm{g}$. Entretanto, contagens de Estafilococos coagulase positiva acima dos parâmetros máximos permitidos pela legislação têm sido encontradas em diversos trabalhos. Como exemplo têm-se as pesquisas desenvolvidas por BROMBERG et al. (2000), GARCIA et al. (2000) e por 
MARQUES et al. (2001), que avaliaram esse mesmo tipo de alimento comercializado em Campinas (SP), Londrina (PR) e Lavras (MG), respectivamente.

Com relação a Clostridios sulfito redutores verificou-se que as contagens obtidas apresentaram-se sempre de acordo com os padrões estabelecidos pela legislação vigente. Não foram encontrados em nenhuma das amostras analisadas (Tabela 2), assim como GARCIA et al. (2000) e MARQUES et al. (2001) também não detectaram a presença desse grupo de microrganismos nas amostras pesquisadas (Londrina e Lavras (MG), respectivamente). BROMBERG et al. (2001), trabalhando com 376 amostras de lingüiça frescal (cidade de Campinas -SP), encontraram esse grupo bacteriano em apenas $0,6 \%$ das amostras. Do grupo dos Clostridios sulfito redutores, Clostridium perfringens é o principal representante. A temperatura de refrigeração em que o produto é armazenado, aliada a competição exercida pela microbiota psicrotrófica acompanhante podem dificultar o crescimento do microrganismo (FORSYTHE, 2002)

Levando-se em consideração apenas a enumeração de Coliformes fecais verificou-se, que $3,57 \%$ das amostras apresentaram-se em desacordo com os parâmetros máximos permitidos pela legislação vigente (Tabela 2). GARCIA et al. (2000), BROMBERG et al. (2000) e MARQUES et al. (2001), pesquisando o mesmo tipo de alimento encontraram número mais elevado de amostras em condições higiênico-sanitárias insatisfatórias (6\%, $22,7 \%$ e $25 \%$, respectivamente). MOREIRA et al. (2001) pesquisaram $E$. coli em toda a linha de processamento de lingüiça mista, em indústria da cidade de Araraquara (SP). Encontraram o microrganismo em todos os pontos amostrados, que incluíam a matéria-prima (carne bovina e suína), superfícies de equipamentos e utensílios, mãos de manipuladores, condimentos e produto final.

O fato de se encontrar número menor de amostras com valores acima dos padrões em vigor, em relação aos trabalhos citados, pode estar relacionado à mudança na legislação da ANVISA, ocorrida em janeiro de 2001. Os parâmetros estabelecidos pelas duas legislações (Tabela 1) evidenciam maior tolerância para Estafilococos coagulase positiva, Coliformes a $45^{\circ} \mathrm{C}$ (Coliformes fecais) e Clostridios sulfito redutores em alimentos enquadrados como "produtos cárneos crus, refrigerados ou congelados", como as lingüiças do tipo frescal.

Utilizou-se o teste $Z$ para comparar as probabilidades de se encontrar amostras não enquadradas nos padrões das legislações atual e anterior para a enumeração de Coliformes fecais (Tabela 3). 
Com a alteração introduzida na legislação a probabilidade de se encontrar amostras de lingüiça mista frescal contaminadas com Coliformes fecais passou de 23,27\% para 5,6\%. Apesar da análise estatística ter sido baseada em espaço amostral pequeno (32 amostras) em relação ao total de lingüiças mistas produzidas na cidade de Pelotas (no período 20002001), o resultado demonstra aumento no risco desse tipo de alimento estar contaminado com outras bactérias patogênicas (devido ao fato dos coliformes serem microrganismos indicadores). Além disso, destaca-se o fato de que diversas linhagens de Escherichia colipodem ser patogênicas ao homem (JAY, 1992; FORSYTHE, 2002).

\section{TABELA 3 - TESTE Z PARA DETERMINAÇÃO DE COLIFORMES FECAIS (LOG NMP $/ g^{-1}$ ), EM 32 AMOSTRAS DE LINGÜIÇAS MISTAS DO TIPO FRESCAL COMERCIALIZADAS EM PELOTAS (RS)}

\begin{tabular}{cccccc}
\hline MØdia & Desvio padr ${ }^{\mathrm{a}} \mathrm{o}$ & $\mathrm{Z}^{\mathrm{a}}$ & $\mathrm{Z}^{\mathrm{b}}$ & Probabilidade $^{\mathrm{a}}$ & Probabilidade $^{\mathrm{b}}$ \\
\hline 1,89 & 1,10 & 0,73 & 1,64 & $76,73 \%$ & $94,94 \%$
\end{tabular}

a) valor calculado no teste $Z$ para amostras com contagem de Coliformes a $45^{\circ} \mathrm{C}$ menores que $5 \times 10^{2} \mathrm{NMP} / \mathrm{g}$;

b) valor calculado no teste $\mathrm{Z}$ para amostras com contagem de Coliformes a $45^{\circ} \mathrm{C}$ menores que $5 \times 10^{3} \mathrm{NMP} / \mathrm{g}$.

\section{CONCLUSÃO}

A percentagem de amostras em desacordo com os padrões estabelecidos pela legislação da ANVISA (presença de Salmonella sp em 17,86\% e Coliformes fecais acima do limite máximo em 3,57\%) é preocupante com relação à saúde dos consumidores desse tipo de alimento, produzido e comercializado em Pelotas (RS). A alteração introduzida na legislação, com o aumento dos valores máximos permitidos para Estafilococos coagulase positiva, Coliformes a $45^{\circ} \mathrm{C}$ e Clostridios sulfito redutores em produtos cárneos crus aumenta a probabilidade de consumo de alimentos contaminados com microrganismos patogênicos. 


\begin{abstract}
MICROBIOLOGICAL QUALITY OF MIXING SAUSAGES OF THE FRESCAL TYPE PRODUCED IN PELOTAS - RS

The hygienic-sanitary conditions of mixing sausages of the frescal type were evaluated, proceeding from 4 slaughterhouses with state sanitary inspection and commercialized in Pelotas (RS). The results were interpreted by the current legislation or the previous one, both of the Brazilian Health Ministry, in the interpretation of the results. It was verified that, $17,86 \%$ of the 32 samples were contaminated with Salmonella sp and $3.57 \%$ presented faecal coliforms above of the parameter allowed by the current legislation. With the change of the legislation, the probability to find samples of frescal mixing sausage with countings of faecal coliforms above of the maximum limits allowed by the legislation, passed of $23,27 \%$ to $5,6 \%$.

KEY-WORDS: SAUSAGES-SALMONELA; SAUSAGES-FAECAL COLIFORMS; SAUSAGES-BRAZILIAN LEGISLATION.
\end{abstract}

\title{
REFERÊNCIAS
}

1 BOOK, S. A. Statistics: basic techniques for solving applied problems. New York: MacGraw-Hill Book, 1977. 511 p.

2 BRASIL. Ministério da Saúde. Portaria 451, de 19 de setembro de 1997. Regulamento técnico. Princípios gerais para o estabelecimento de critérios e padrões microbiológicos para alimentos. Diário Oficial [da] República Federativa do Brasil, Brasília, n. 182, p. 2100521011, 22 set. 1997. Seção I.

3 BRASIL. Ministério da Saúde. Resolução RDC no 12, de 02 de janeiro de 2001. Regulamento técnico sobre padrões microbiológicos para alimentos. Diário Oficial [da] República Federativa do Brasil, Brasil, n. 7-E, p. 46-53, 10 jan. 2001. Seção I.

4 BROMBERG, R.; YAMADA, E.A.; MIYAGUSKU, L. Estudos da qualidade microbiológica de carnes e produtos cárneos crus resfriados. In: Congresso Brasileiro de Ciência e Tecnologia de Alimentos, 17, Fortaleza, 2000. Resumos... Fortaleza: SBCTA, Universidade Federal do Ceará. 2000. v.1, p.122.

5 DELAZARI, I.; LEITÃO, M. F. F.; HSU, L. A. Efeito da microflora contaminante sobre o desenvolvimento de Staphylococcus aureus em lingüiças. Coletânea do ITAL, Campinas, v. 8, p. 557-71, 1978. 
6 FERREIRA, M. G. A. B., SOBRINHO, A. J. C. Avaliação bacteriológica de carnes bovina moída e suína (pernil) "in natura" e/ ou refrigerada comercializados em São Luís/MA. In: CONGRESSO BRASILEIRO DE MICROBIOLOGIA, 21, Foz do Iguaçu, 2001. Resumos... Foz do Iguaçu: Armazém das Letras, 2001. p. 378.

7 FDA. Food and Drug Administration. Bacteriological analytical manual. $7^{\text {th }}$ ed. Arlington: AOAC International, 1992.

8 FORSYTHE, S.J. Microbiologia da segurança alimentar. São Paulo: Artmed, 2002. 424 p.

9 GALARDA, I.; LIMA, M.L.P.S; MIKOSZEWSKA, I.; ELIAS, A. Pesquisa de Salmonella em produtos alimentares de origem animal. B. CEPPA. Curitiba, v. 9, n. 2, p. 170-177, 1999.

10 GARCIA, S. et al. Avaliação da segurança microbiológica de lingüiças tipo frescal coletadas no município de Londrina. In: CONGRESSO BRASILEIRO DE CIÊNCIA E TECNOLOGIA DE ALIMENTOS, 17., Fortaleza, 2000. Resumos... Fortaleza: SBCTA, Universidade Federal do Ceará. 2000. v.1, p.112.

11 GELLI, D.S. et al. Surtos de enfermidades transmitidas por alimentos (ETA's) investigados pelos Laboratórios de Saúde Pública do estado de São Paulo, no período de 1994 a 1998. In: CONGRESSO BRASILEIRO DE MICROBIOLOGIA, 20, Salvador, 1999. Resumos... Salvador: Armazém das Letras, 1999. p. 376.

12 JAY, J.M. Microbiologia moderna de los alimentos. 4.ed. Zaragoza: Editorial Acribia, 1992.

13 LOGUERCIO, A. P. Avaliação de desempenho de um ELISA indireto na detecção de Salmonella sp em lingüiça suína. Pelotas, 2001. 23 p. Dissertação (Mestrado em Ciência e Tecnologia Agroindustrial) - Faculdade de Agronomia Eliseu Maciel, Universidade Federal de Pelotas.

14 MARQUES, S.C. et al. Qualidade higiênico-sanitária de lingüiças tipo frescal comercializadas no município de Lavras (MG). In: CONGRESSO BRASILEIRO DE MICROBIOLOGIA, 21, Foz do Iguaçu, 2001. Resumos... Foz do Iguaçu: Armazém das Letras, 2001. p. 394. 
15 MOREIRA, F.C. et al. Qualidade microbiológica na linha de processamento de lingüiça mista. In: CONGRESSO BRASILEIRO DE MICROBIOLOGIA, 21, Foz do Iguaçu, 2001. Resumos... Foz do Iguaçu: Armazém das Letras, 2001. p. 369.

16 NOGUEIRA PINTO, J.P.A. et al. Avaliação microbiológica de produtos embutidos encaminhados ao Serviço de Orientação à Alimentação Pública (SOAP) da DMVZ, UNESP, Campus de Botucatu. In: CONGRESSO BRASILEIRO DE HIGIENISTAS DE ALIMENTOS, 5., 1999, Foz do Iguaçu: GT Editora. R. Higiene Alimentar, v.13, n.61, p. 69, 1999.

17 REIS, R.B.; KRUGER, C.S.; MACIEL, M.S. Salmonella sp em produtos cárneos comercializados no município de Cuiabá-MT. Avaliação da metodologia de pesquisa. Modelos de resistência a drogas antimicrobianas. Ciência e Tecnologia de Alimentos, Campinas, v.15, n.1, p. 74-78, 1995.

18 RIO GRANDE DO SUL. Secretaria Estadual de Saúde e do Meio Ambiente. Divisão de Vigilância Sanitária. Relatórios anuais de enfermidades transmitidas por alimentos (ETA) - 1987-1998. Porto Alegre, 1998. 